UDC 613.495:615.07

https://doi.org/10.33573/ujoh2021.04.272

\title{
ANALYTICAL ISSUES OF COSMETIC SAFETY ASSESSMENT METHODOLOGY (LITERATURE REVIEW)
}

\author{
Yastrub T. O., Prygunova V. V., Khudenko N. V., Dontsova D. O., \\ Hrygorieva K. V., Kovalenko V. F.

\section{State Institution «Kundiiev Institute of Occupational Health of the National Academy of Medical Sciences of Ukraine», Kyiv}

Introduction. Since July 2013, the European Union (EU) imposed a ban on testing cosmetic products on animals, this ban is supported by a number of countries in the world, including Ukraine. Alongside with this, the issue of introducing alternative methods of testing cosmetic products, determining the toxicological endpoints and testing strategies for new ingredients is relevant. The article provides a practical overview of methods for assessing the safety of cosmetic products, taking into account the current approaches used in the EU.

The aim of the study - analytical review of modern methods of assessing the safety of cosmetic products.

Materials and methods of research. The study is based on the analysis of local and foreign publications, current regulations and guidance documents of international organizations governing the circulation of cosmetics.

Results. Assessing the safety of cosmetic products involves various approaches, including animal testing data (in vivo) conducted before 2013, methods using cell lines and tissues (in vitro), and computer simulation methods (in silico). The damaging effects of cosmetic products on the skin are most often evaluated using three-dimensional models of artificial skin, and the damaging effects on the eyes are investigated both by methods of cellular analysis and using the eyes of dead animals. At the same time, the available alternative methods do not meet the need to assess all toxicological parameters (acute toxicity, embryonic toxicity, endocrine toxicity, carcinogenicity, and repeated-dose assessment). Under such conditions, computer modeling methods are of particular relevance.

Conclusions. Assessing the safety of cosmetic products requires careful planning and development of testing strategies that include searching for available information on tests performed on animals, using alternative in vitro models, and involving in silico methods.

Key words: cosmetic products, safety assessment, alternative methods, computer simulation methods 


\section{Introduction}

In July 2013, the Regulation of the European Parliament and of the Council of 30 November 2009 No. 1223/2009 on cosmetic products (EU Regulation) came into force, aimed at protecting the health of consumers, establishing rules for assessing product safety and banning research on animals. Based on the EU Regulation, Ukraine established the Technical Regulation on Cosmetic Products, approved by the Cabinet of Ministers of Ukraine on 20 January 2021 (the Technical Regulation). The main objectives of the adoption of the Technical Regulation are harmonization of technical requirements with the European legislation and elimination of legal, administrative and technical barriers to trade with EU countries. The Technical Regulation places additional emphasis on the safety assessment of cosmetic products to be carried out without the use of animals. In the new regulatory environment, effective planning and development of testing strategies come to the fore, which is particularly relevant when new ingredients are available.

The aim of the study - analytical review of current methods for assessing the safety of cosmetic products.

\section{Materials and methods of research}

The study is based on the analysis of local and foreign publications, current regulations and guidance documents of international organizations governing the circulation of cosmetics.

\section{Research results and their discussion}

In the EU, the circulation of cosmetic products is regulated by a number of organisations, the most important among which are the following: 1) The European Centre for the Validation of
Alternative Methods (EURL ECVAM) - plays a key role in the development, validation and recognition of alternative methods in the EU; 2) The Scientific Committee on Consumer Safety (SCCS) - provides conclusions on health and safety risks of non-food consumer products (cosmetic products and their ingredients, toys, textiles, clothing, personal care and household products) and services; algorithms for cosmetics safety assessment; 3) The EU Regulation (Registration, Evaluation, Authorisation and iction of Chemicals, REACH) - The organisation responsible for assessing, authorising or restricting the handling of chemicals. The aims of REACH include ensuring a high level of protection of human health and the environment from the use of chemicals and promoting the use of alternative methods of assessing the hazardous properties of substances, such as Quantitative Structure-Activity Relationship (QSAR); 4) International Organisation for Economic Cooperation and Development (OECD) - provides testing guidelines for chemicals that can be used for cosmetic product research.

Taking into account that the Technical Regulation is based on the EU Regulation, the principles of safety assessment of cosmetic products, implemented in accordance with the recommendations of the above-mentioned organizations, may be acceptable in Ukraine.

In order to meet the requirements of the Technical Regulation, the cosmetic product expert should carry out a detailed evaluation of the ingredients and the finished cosmetic composition and draw up a report on the safety of the cosmetic product, with due justification for the absence of certain indicators. From a practical point of view, the most significant and time-consuming task is to obtain the report data on the toxicological profile of substances. 
In assessing the toxicological profile, the cosmetic expert should analyse the following:

1) Local toxicity data from alternative test models (skin and eye irritation, skin sensitisation, phototoxicity and systemic effects);

2) In vivo data to assess the Margin of Safety (MoS) of ingredients in cosmetic products, justified at the No Observed Adverse Effect Level (NOAEL);

3) In cases where the above-mentioned sources do not provide the necessary information, in silico methods are useful for safety assessment.

In the EU, local and systemic effects of cosmetic products are assessed using alternative models approved by EURL ECVAM and included in OECD algorithms (Table 1).

The damaging effects on the skin are investigated using three-dimensional artificial skin models, which include EpiSkin ${ }^{\mathrm{TM}}$, EpiDerm ${ }^{\mathrm{TM}}$, SkinEthic $^{\mathrm{TM}}$ and epiCS ${ }^{\circledR}$ tissue (OECD 431 skin corrosion, OECD 439 - skin irritation). In these OECD algorithms, cell viability is assessed as an endpoint using a colorimetric method (MTT-test). A limitation of the OECD 439 algorithm is that aerosols and gases cannot be used, and testing substances that absorb light in the same range as MTT formazan and dyes will require additional adapted controls and a more careful interpretation of results. Threedimensional models of artificial skin mimic the function of real human skin in vivo, but incomplete maturation of the stratum corneum may be the cause of impaired barrier function and consequent increased ingredient permeability [12].

In addition to three-dimensional artificial skin models, the Corrositex ${ }^{\circledR}$ membrane (OECD 435 Skin Membrane Barrier Test Method) can be used to evaluate the damaging effects of certain classes of chemicals. The Corrositex ${ }^{\circledR}$ membrane is a reconstituted collagen matrix with physical properties similar to those of rat skin. The method for testing the membrane barrier is based on determining the time it takes for the test material to pass through the membrane into the chemical detection system. The test system consists of two components: a biomembrane and a chemical detection system (Chemical Detection System, CDS). Damage to the membrane barrier is revealed by the CDS either by a color change in the indicator solution (due to $\mathrm{pH}$ change) or by a change in consistency at the sample/test liquid interface. The assigned classification of a chemical is based on the time (in minutes) it takes for the chemical to penetrate the membrane barrier. This method is used to test solids (soluble or insoluble in water), liquids and emulsions; the samples may be pure chemicals, solutions or mixtures. The method is considered suitable for limited applications, namely acids, bases and their derivatives, and is not applicable to gases and aerosols; also this method does not provide information on skin irritation [13, 3].

Eye damage is assessed using three-dimensional corneal models - EpiOcular ${ }^{\mathrm{TM}}$ and SkinEthic ${ }^{\mathrm{TM}}$ HCE (OECD 492 - method for assessing corneal irritation or damage). The three-dimensional corneal models consist of corneal epithelial tissue, as it is the first point of contact with the external environment and is considered the most important part for eye irritation assessment. The models are grown on a permeable base and differ only in the source of the cells. EpiOcular ${ }^{\mathrm{TM}}$ tissues use normal human skin keratinocytes differentiated into stratified squamous ocular epithelium and SkinEthic ${ }^{\mathrm{TM}} \mathrm{HCE}$ tissues use human corneal cells [14]. The damaging effect of the chemical is assessed by measuring cell viability using the MTT test [4].

Eye damage is also investigated using a rabbit corneal cell line (OECD 491 - short-term exposure hazard potential assessment) and a dog kidney tubular epithelial cell monolayer (OECD 460 fluorescein leakage test method). 
Alternative models approved by EURL ECVAM

\begin{tabular}{|c|c|c|c|}
\hline Model in vitro & Producer & Model Characteristics & OECD \\
\hline EpiSkin ${ }^{\mathrm{TM}}$ & $\begin{array}{l}\text { Skin Ethics } \\
\text { Laboratories }\end{array}$ & Reconstructed equivalent of human epidermis & $\begin{array}{l}\text { OECD } 431[1] \\
\text { OECD } 439[2]\end{array}$ \\
\hline EpiDerm $^{\mathrm{TM}}$ & Mat Tek Corporation & Reconstructed equivalent of human epidermis & $\begin{array}{l}\text { OECD } 431[1] \\
\text { OECD } 439[2]\end{array}$ \\
\hline SkinEthic ${ }^{\mathrm{TM}}$ & $\begin{array}{l}\text { Skin Ethics } \\
\text { Laboratories }\end{array}$ & Reconstructed equivalent of human epidermis & $\begin{array}{l}\text { OECD } 431[1] \\
\text { OECD } 439[2]\end{array}$ \\
\hline epiCS ${ }^{\circledR}$ & Cell Systems & Reconstructed equivalent of human epidermis & $\begin{array}{l}\text { OECD } 431[1] \\
\text { OECD } 439[2]\end{array}$ \\
\hline Corrositex $^{\circledR}$ & In Vitro International & $\begin{array}{l}\text { Biomembrane and detection system of certain } \\
\text { classes of chemicals }\end{array}$ & OECD 435 [3] \\
\hline $\begin{array}{l}\text { SkinEthic } \\
\text { HCE }\end{array}$ & SkinEthic Laboratories & Epithelial cells of the human cornea & OECD $492[4]$ \\
\hline EpiOcularTM & MatTek Corporation & Epithelial cells of the human cornea & OECD $492[4]$ \\
\hline SIRC & - & $\begin{array}{l}\text { Monolayer of rabbit corneal cells (Statens } \\
\text { Seruminstitut Rabbit Cornea) }\end{array}$ & OECD $491[5]$ \\
\hline MDCK & - & Epithelial cells of the dog's kidney & OECD $460[6]$ \\
\hline $\begin{array}{l}\text { Cornea of the } \\
\text { isolated eye of } \\
\text { cattle }\end{array}$ & - & - & OECD 437 [7] \\
\hline $\begin{array}{l}\text { Cornea isolated } \\
\text { eye of chickens }\end{array}$ & - & - & OECD $438[8]$ \\
\hline $\mathrm{BALB} / \mathrm{c} 3 \mathrm{~T} 3$ & - & Constant line of mouse fibroblast cells & $\begin{array}{l}\text { OECD } 432[9] \\
\text { OECD } 129[10]\end{array}$ \\
\hline U937 & - & Histiocytic lymphoma cell line & OECD 442 E [11] \\
\hline THP-1 & - & Histiocytic lymphoma cell line & OECD 442 E [11] \\
\hline
\end{tabular}


Rabbit cornea cells (Statens Seruminstitut Rabbit Cornea, SIRC) are often used for ophthalmic drug testing as a model of the corneal epithelial barrier to study permeability. Evaluation of ocular hazard potential by short-term exposure involves the study of cytotoxicity by measuring SIRC cell viability using the MTT test after $5 \mathrm{mi}-$ nutes exposure to two concentrations of the test substance ( $5 \%$ and $0.5 \%$ ). Reduced cell viability is used to predict possible adverse effects leading to ocular damage [5].

Madin-Darby Canine Kidney epithelial cells (MDCK) are grown on semi-permeable inserts and mimic the non-proliferative state of the corneal epithelium. MDCK cells form tight intercellular contacts similar to those found on the apical side of the conjunctival and corneal epithelium and prevent foreign substances from entering the corneal epithelium. The essence of the fluorescein leakage test method for detecting ocular corrosion and strong irritants is as follows. The test substance is applied to the layer of MDCK cells growing on the apical side of the insert (about 1 minute), after removing the test substance, fluorescein is applied for $30 \mathrm{~min}$ utes. The presence of damage is determined by spectrofluorometric measurement of fluorescein concentration, which penetrates through the cell monolayer over a period of time. Loss of the transepithelial barrier due to desmosomal damage is one of the early events in chemical-induced eye irritation [6].

The eyes of dead animals (cattle and chickens' eyes) are used to assess severe eye damage. Damage can be assessed by quantifying changes in opacity (i. e. the amount of light transmitted through the cornea), permeability (estimating the amount of fluorescein dye that passes through the entire corneal thickness), corneal edema, corneal opacity and pathohistological measurements $[7,8]$.

EURL ECVAM has now approved a number of cell models that can be used in cosmetic evaluation protocols. A mouse fibroblast cell line (Balb/c 3T3) is used to evaluate phototoxicity (OECD $432-$ in vitro $3 \mathrm{~T} 3 \mathrm{NRU}$ phototoxicity test) and acute toxicity (OECD 129 - initial dose selection test for oral toxicity in systemic toxicity studies). (U937) and human monocytic leukaemia (THP-1) - for assessment of skin sensitization (OECD $442 \mathrm{E}-$ in vitro skin sensitization test).

Phototoxicity is defined as a toxic response resulting locally or systemically from exposure to photoreactive chemicals to ambient light. The in vitro $3 \mathrm{~T} 3 \mathrm{NRU}$ phototoxicity test is based on comparing the cytotoxicity of a chemical when tested in the presence and absence of the effects of a non-cytotoxic dose of sunlight simulated using Balb/c 3T3 cells. Cytotoxicity in this test is expressed as a decrease in the uptake of the neutral dye vitamin dye after treatment with the test chemical and irradiation [9].

The acute toxicity method is an approach that evaluates the uptake of neutral red dye by Balb/c $3 \mathrm{~T} 3$ cells in the presence of the test chemical. The method is used to determine the initial doses of acute oral toxicity tests and reduces the number of animals required for studies (from 6 to 3 ). This method may be acceptable for the evaluation of substances acting solely because of basal cytotoxicity and not requiring any activation or transformation before manifesting their toxic effects. Given that this method only reduces the number of animals in the experiment, it is advisable to consider it in combination with other data and information obtained from the use of in silico methods [10].

It should be noted that in addition to acute toxicity, evaluation of the systemic effects of cosmetic products includes data on carcinogenicity, embryo toxicity; endocrine effects and assessment of repeated doses, however, alternative models for testing these indicators are not yet available.

At present, a complete replacement of animal testing to assess skin sensitization requires testing 
strategies combining several methods, namely a combination of in chemico, in vitro and in silico methods. It is currently unclear how many different key events in the sensitization mechanism should be considered. One of the key events in skin sensitisation concerns dendritic cell activation, which is accompanied by the expression of specific cell surface markers, CD86 and CD54. CD86 is known to be a costimulatory molecule that can mimic monocyte activation, which plays an important role in priming T cells.

Methods using histiocytic lymphoma cells (U937 Cell Line Activation Test, U-SENS) and human monocytic leukemia (human Cell Line Activation Test, h-CLAT) simulate dendritic cell activation under the action of test chemicals. Like dendritic cells, upon contact with sensitizers, human histiocytic lymphoma cells (U-SENS) and human monocytic leukemia cells (h-CLAT) are activated and increase the expression of surface markers, which is measured by flow cytometry after cell staining. A limitation of both methods is the testing of fluorescent substances that affect detection by flow cytometry and the use of substances that disrupt the cell membrane as surfactants can lead to false positives [11, 13, 15].

The MoS value of chemicals is mainly calculated on the basis of oral toxicity studies if reliable dermal toxicity data are not available. MoS is estimated using Points of Depature (POD) and Systemic Exposure Dose (SED). In toxicology, a POD is three points on an experimentally determined doseeffect curve: 1) NOAEL; 2) the Lowest Observed Adverse Effect Level (LOAEL); 3) the statistical reference dose (benchmark dose, BMD) [16].

If BMD or NOAEL cannot be determined from available data, LOAEL data may be used in the calculation of MoS.

The SCCS guidelines ( $10^{\text {th }}$ edition) introduce the concept of PODsys to estimate the MoS of cosmetic products. PODsys is the systemic expo- sure dose of a substance calculated from an oral POD (BMD, NOAEL or LOAEL) using the absorbed substance particle.

That is, PODsys can only match the oral NOAEL when there is information that gastrointestinal absorption is $100 \%$.

For most substances and by default, when the absorption of the test substance is unknown, the oral bioavailability is only $50 \%$, so the NOAEL should be divided by 2 to obtain PODsys.

If there is information indicating poor oral bioavailability (e. g. poor particle solubility), a $10 \%$ default oral absorption may be used.

For the estimation of systemic exposure dose, i. e. SED, the SCCS guidelines ( $10^{\text {th }}$ edition) provide 2 methods of calculation. The first method is based on the absolute amount of bioavailable substance ( $\mu \mathrm{g} /$ $\mathrm{cm}^{2}$ ) after a certain period of time, based on the highest estimated concentration. In this case, to estimate the systemic availability of the substance, it is necessary to know the standard skin surface area (SSA) value for each product type (data are given in annex 3 of the SCCS guidelines, $10^{\text {th }}$ edition). The second method of assessment is based on the percentage absorbed dermally. This depends on the amount of finished product applied to the skin. The formulas for calculation are given (Table 2).

The default MoS value of 100 is generally accepted. Therefore, a calculated MoS of at least 100 means that the cosmetic ingredient is safe for use.

The Mos value of 100 consists of a factor of $10-$ for extrapolation from test animals to humans (interspecies extrapolation) and another factor of 10 to account for variation in the human population (intraspecies extrapolation) (Figure) [17].

In order to fill data gaps in cases where in vitro studies do not provide the necessary information due to lack of an approved alternative method and no data from in vivo studies for safety assessment are available, in silico methods are appropriate. 
Methods of assessing the degree of safety

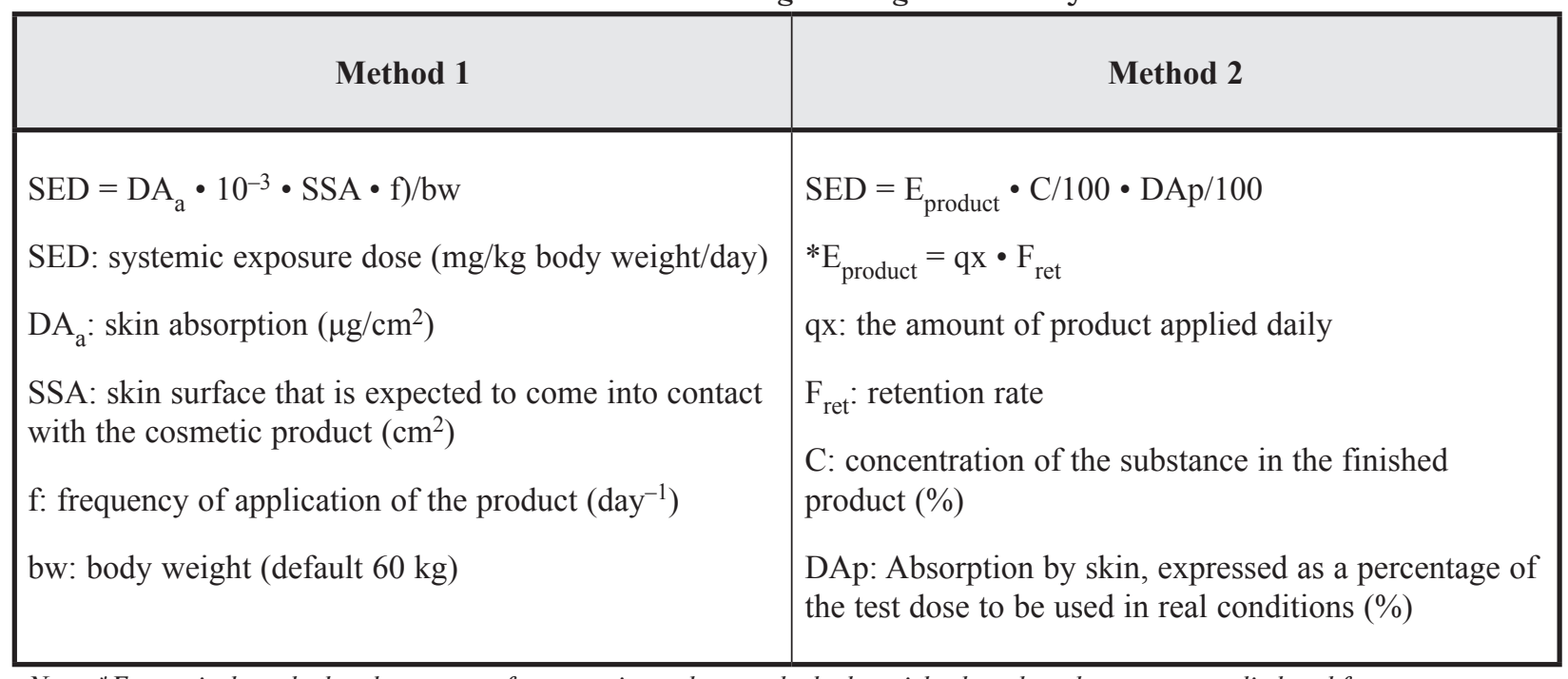

Note: ${ }^{*} E_{\text {product }}$ is the calculated exposure of a cosmetic product per $\mathrm{kg}$ body weight, based on the amount applied and frequency of application ( $\mathrm{mg} / \mathrm{kg}$ body weight/day) [17].

The availability of high quality chemical/effect databases, powerful data retrieval algorithms and increasing computing power in recent decades have led to more versatile and robust tools and systems for toxicity modelling. In silico methods based on Structure-activity relationship (SAR) modelling offer an alternative approach to chemical toxicity assessment without experimental data. These methods have become particularly important as they offer a rapid, cost effective and ethical alternative to chemical toxicity testing in animals. Computer-assisted prediction of the toxicity of chemical compounds began to develop in the 1980s. This was due to the high costs of experimental toxicology research, the social movement for animal welfare and the large number of chemical compounds available not only for screening but also for more in-depth studies. The basis of computerized toxicity prediction is basic research that permits the delineation of plausible relationships between chemical and toxic qualities [18]. The main in silico methods used to assess cosmetic product toxicity and recommended by the SCCS guidelines include QSAR and the Readacross chemical grouping method [17, 19].
Both methods are based on the principle of similarity, i. e. similar molecules have similar qualities and the biological activity is determined by the molecular structure. QSAR methods are statistical in nature as they attempt to relate the molecular descriptors of chemicals to their properties. In addition, these methods are global in scope - they build models for all chemicals in a given data set and make predictions for a wide range of chemicals within an application [20].

Read-across is perhaps the simplest of the in silico approaches for filling gaps in toxicological data on cosmetic ingredients. This method is based on the premise that similar compounds will have similar properties and activities; hence, the toxicity of one molecule can be interpolated to another [21]. This approach is local because its predictions are based on the properties of a small set of similar chemicals. Similarities can be based on common functional groups, modes or mechanisms of action, chemical classes, etc. In other words, a method allows us to foresee unknown properties of chemicals of interest based on the known properties of chemicals in the same chemical group [20]. QSARs 

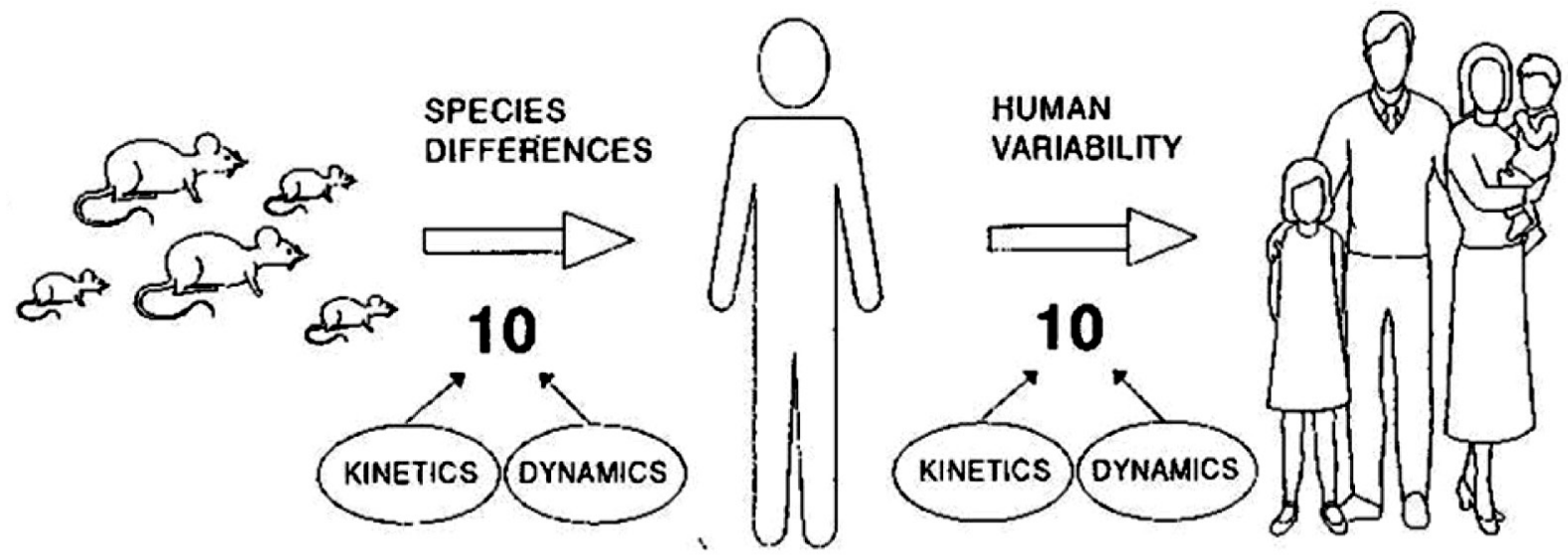

Figure. Schematic representation of extrapolation from animals to humans

are general models for which detailed knowledge of the property may not be as explicit and detailed as for Read-across. Read-across methods often focus on specific chemicals, the information they provide may include data not considered in QSAR models (e. g. target organ data, mechanism of action, etc.). On the other hand, QSAR models may use well-defined parameters (e. g. polarity, solubility, presence of a certain active moiety) and thus constitute a general scientific basis for prediction [19].

QSAR and Read-across methods are implemented in freely available software platforms such as QSAR ToolBox, VEGA QSAR, Benigni/Bossa rulebase, Hazard Evaluation Support System Integrated Platform, Toxmatch and ToxRead.

\section{Conclusions}

1. The evaluation of the safety of cosmetic products involves the analysis of a considerable amount of data obtained both by experimental studies and by non-experimental research methods (in silico methods).

2. Alternative methods of testing cosmetic products used by EU countries do not meet the need to determine all the necessary toxicological indicators (acute toxicity, embryo toxicity, effects on endocrine organs, carcinogenicity, repeated-dose studies).

3. Computer modelling techniques are an important part of the safety assessment of cosmetic products in the absence of experimental data as part of a multilevel testing strategy. 


\section{References}

1. Organization for Economic Cooperation and Development. (2019), OECD Guidelines for the Testing of Chemicals - Guideline 431: In Vitro Skin Corrosion: Reconstructed Human Epidermis (RhE) Test Method.

2. Organization for Economic Cooperation and Development. (2021), OECD Guidelines for the Testing of Chemicals - Guideline 439: In Vitro Skin Irritation: Reconstructed Human Epidermis Test Method.

3. Organization for Economic Cooperation and Development. (2015), OECD Guidelines for the Testing of Chemicals - Guideline 435: In Vitro Membrane Barrier Test Method for Skin Corrosion.

4. Organization for Economic Cooperation and Development. (2019), OECD Guidelines for the Testing of Chemicals - Guideline 492: Reconstructed Human Cornea-Like Epithelium (Rhce) Test Method For Identifying Chemicals Not Requiring Classification And Labelling For Eye Irritation Or Serious Eye Damage.

5. Organization for Economic Cooperation and Development. (2020), OECD Guidelines for the Testing of Chemicals - Guideline 491: Short Time Exposure In Vitro Test Method For Eye Hazard Potential.

6. Organization for Economic Cooperation and Development. (2017), OECD Guidelines for the Testing of Chemicals - Guideline 460: Fluorescein Leakage Test Method for Identifying Ocular Corrosives and Severe Irritants.

7. Organization for Economic Cooperation and Development. (2020), OECD Guidelines for the Testing of Chemicals - Guideline 437: Bovine Corneal Opacity And Permeability Test Method For Identifying i) Chemicals Inducing Serious Eye Damage And ii) Chemicals Not Requiring Classification For Eye Irritation Or Serious Eye Damage.

8. Organization for Economic Cooperation and Development. (2018), OECD Guidelines for the Testing of Chemicals - Guideline 438: Isolated chicken eye test method for identifying I) chemicals inducing serious eye damage and II) chemicals not requiring classification for eye irritation or serious eye damage.

9. Organization for Economic Cooperation and Development. (2019), OECD Guidelines for the Testing of Chemicals - Guideline 432: In Vitro 3T3 NRU Phototoxicity Test.

10. Organization for Economic Cooperation and Development. (2010), OECD Guidelines for the Testing of Chemicals - Guideline 129: Guidance document on using cytotoxicity test to estimate starting doses for acute oral systemic toxicity tests.
11. Organization for Economic Cooperation and Development. (2018), OECD Guidelines for the Testing of Chemicals - Guideline 442E: In Vitro Skin Sensitisation: In Vitro Skin Sensitisation Assays Addressing the Key Event on Activation of Dendritic Cells on the Adverse Outcome Pathways for Skin Sensitisation.

12. Hwang, J. H., Jeong, H., Lee, N. et al. (2021), «Ex vivo live full-thickness porcine skin model as a versatile in vitro testing method for skin barrier research", International Journal of Molecular Sciences, No. 22, pp. 1-16, https://doi.org/10.3390/ijms22020657.

13. Eskes, C., Vliet, E., Maibach, H. I. (2017), "Alternatives for dermal toxicity testing. Springer International Publishing", 592 p., https://doi. org/10.1007/978-3-319-50353-0 43.

14. Wilson, S. L., Ahearne, M., Hopkinson, A. (2015), "An overview of current techniques for ocular toxicity testing", Toxicology, No. 327, pp. 32-46, https://doi. org/10.1016/j.tox.2014.11.003.

15. Kim, K., Kwack, S. J., Lee, J. Y. et al. (2021), "Current opinion on risk assessment of cosmetics", Journal of Toxicology and Environmental Health - Part B: Critical Reviews, No. 24, pp. 137-161, https://doi.org/ 10.1080/10937404.2021.1907264.

16. Boobis, A. R., Crofton, K. M., Heinemeyer, G. et al. (2015), World Health Organization, «Risk assessment of combined exposure to multiple chemicals", $36 \mathrm{p}$.

17. Scientific Committee on Consumer Safety SCCS. The SCCS note of Guidance for the testing of cosmetic ingredients and their safety evaluation $-10^{\text {th }}$ Revision. (2018).

18. Bobkova, L. S., Chekman, I. S., Yavorovski, A. P. (2008), "Use of GSAR in toxicology" [Zastosuvannia metodu qsar v toksykolohii»], Sovremennye problemy toksykolohyy, No. 2, pp. 78-86.

19. Benfenati, E., Chaudhry, Q., Gini, G. et al. (2019), "Integrating in silico models and read-across methods for predicting toxicity of chemicals: A step-wise strategy", Environment International, No. 131 (4), pp. 1-15, https:// doi.org/10.1016/j.envint.2019.105060.

20. Chushak, Y. G., Shows, H. W., Gearhart, J. M. et al. (2018), "In silico identification of protein targets for chemical neurotoxins using ToxCast in vitro data and read-across within the GSAR toolbox", Toxicology Research, No. 7, pp. 423-431, https://doi.org/ 10.1039/C7TX00268H.

21. Rogiers, V., Benfenati, E., Bernauer, U. et al. (2020), "The way forward for assessing the human health safety of cosmetics in the EU - Workshop proceedings", Toxicology, No. 436, pp. 1-14, https://doi. org/10.1016/j.tox.2020.152421. 
ISSN 2223-6775, Ukrainian Journal of Occupational Health, 2021, 17 (4), 272-281

ORCID ID of co-authors and their contribution to the preparation and writing of the article:

Yastrub T. O. (ORCID ID 0000-0002-5084-3773) - the research idea, determination of relevance, formation of the concept, development of the research plan and purpose, summarization of conclusions;

Prygunova V. V. (ORCID ID 0000-0002-4143-488X) - collection of literature data, writing of individual sections of the article;

Khudenko N. V. (ORCID ID 0000-0003-3460-9511) - participation in the formation of conclusions, writing and design of the article;

Dontsova D. O. (ORCID ID 0000-0003-3676-1672) - collection of literature data, preparation of the article for publication;

Hrygorieva K. V. (ORCID ID 0000-0001-8532-1265) - interpretation of literature data, design and preparation of the article for publication;

Kovalenko V. F. (ORCID ID 0000-0003-1157-3560) - analysis and generalization of the obtained data.

Received: October 29, 2021

Accepted for publication: November 24, 2021

Contact person: Yastrub Tetiana Oleksandrivna, Laboratory of Toxicology of Pesticides and Occupational Hygiene at their Use, State Institution «Kundiiev Institute of Occupational Health of the National Academy of Medical Sciences of Ukraine», 75, Saksaganskogo str., Kyiv, 01033. Tel.: + 380442894188.

E-mail: tatyanayastrub@gmail.com 